\title{
OS CLÁSSICOS DA CLIMATOLOGIA GEOGRÁFICA: A CONTRIBUIÇÃO PIONEIRA DE ELLSWORTH HUNTINGTON
}

\author{
Ilton Jardim de Carvalho Junior *
}

Resumo: Este artigo pretende fazer uma releitura crítica de uma das obras mais polêmicas da Geografia, "Civilization and Climate", de Ellsworth Huntington. Autor prolífico e de teorias ousadas e complexas, foi pioneiro na nascente ciência climatológica, ao contribuir para seu avanço teórico, metodológico e epistemológico. Sua obra, injustamente desmerecida por grande parte da crítica, lidou com grandes hipóteses centrais da ciência geográfica, como a relação sociedade-natureza e a controversa teoria das influências ambientais. A análise pormenorizada de "Civilization and Climate", baseada na análise imparcial e justa de alguns comentadores, mostrou que Huntington merece ser lembrado pela seriedade e ousadia de suas pesquisas e idéias, pela complexidade de suas teorias, e pelo pioneirismo de suas metodologias.

Palavras-chave: contribuição teórico-metodológica, climatologia norte-americana, idéia das influências ambientais, clima e desenvolvimento, "Civilização e Clima".

\section{THE CLASSIC AUTHORS OF GEOGRAPHICAL CLIMATOLOGY: THE PRECURSORY CONTRIBUITION OF ELLSWORTH HUNTINGTON}

\begin{abstract}
This essay aims at analyzing the masterwork of Huntington, "Civilization and Climate", one of the most polemic geographical works, in order to show how unfair were the critics launched to Huntington's complex and precursor theories, particularly the environmentalist theory, established from the relation between climate and society. The careful analysis was supported by some renowned scholars who have done an impartial and unbiased job, stressing the positive aspects of Huntington's works, and enlightening his outstanding and innovative theoretical, methodological and epistemological contributions to geography, climatology, and many other fields.
\end{abstract}

Key Words: theoretical-methodological contribution, north american climatology, climate and development, theory of environmental influences, Huntington's Civilization and Climate

\section{Introdução}

Este artigo pretende fazer uma releitura crítica de uma das obras mais polêmicas da Geografia, "Civilization and Climate", de Ellsworth Huntington. Autor prolífico e de teorias ousadas e complexas, foi pioneiro na nascente ciência climatológica, ao contribuir para seu avanço teórico, metodológico e epistemológico. Sua obra, injustamente desmerecida por grande parte da crítica, lidou com grandes hipóteses centrais da ciência geográfica, como a relação sociedade-natureza e a controversa teoria das influências ambientais.

Antes de analisar a polêmica obra de Huntington, é preciso mostrar esse autor sob a ótica de seu biógrafo, Geoffrey Martin, que descreve e analisa traços marcantes da vida profissional e da obra de Huntington em seu livro "Ellsworth Huntington: His Life And Thought". Com base nesse renomado comentador da obra de Huntington, e em outros comentadores que realizaram críticas

\footnotetext{
* Professor doutor em geografia física pela USP, atualmente professor substituto 40 horas na UFRGS. Email: sinfoniaalpina@terra.com.br
} 
ponderadas e produtivas, realizou-se uma releitura da obra "Civilization and Climate", de modo a mostrar a complexidade, o pioneirismo e a atualidade das idéias contidas neste grande clássico da literatura geográfica, que tem sido subestimado e ignorado pela comunidade científica.

Martin abre seu prefácio afirmando que no pensamento de Huntington não há a pretensão de um conhecimento acabado, final, mas apenas uma luta incessante por uma compreensão mais ampla dos fenômenos e da relação entre eles. Huntington atraiu os holofotes dos pensadores de seu tempo, pois usava de uma prosa vigorosa e eloqüente para apresentar inusuais interpretações de eventos históricos (MARTIN, 1973). Logicamente que a platéia não poderia comportar-se de outra forma, que não com certo frisson, afinal, estavam entediados com as explicações sempre em voga e pouco convincentes, relacionadas à política, a economia, aos caprichos humanos. A pergunta central e subjacente não queria calar: que fatores influenciam a política, a economia e os caprichos humanos? De que forma todas essas influências interagiam entre si e com o os fatores ambientais?

Huntington não foi presunçoso quanto aos seus achados, pois não esperava que sua platéia aceitasse suas explanações hipotéticas sem alguma alteração ou reparos, nem ficava irritado com os excessos da crítica. Martin afirma que "Formar um julgamento a respeito de um homem e sua obra com base em apenas um de seus numerosos livros é perder o conjunto coerente de suas idéias"1 (MARTIN, 1973, p.xi). Assim, cabe ao critico ler a obra completa, e não apenas uma obra, pois uma

\footnotetext{
${ }^{1}$ Todas as citações deste artigo foram traduzidas pelo autor com base no original em inglês.
}

grande figura como Huntington não pode ser reduzido a apenas uma de suas obras. Além de geógrafo e estudante contumaz das civilizações, estudou as oscilações climáticas, estabeleceu os princípios da variabilidade climática, buscou o optimum climático, estudou os resultados da seleção natural, optou pelo eugenismo, descreveu as qualidades do ozônio e investigou fenômenos cíclicos em várias partes do planeta, principalmente na Ásia, onde se dedicou ao estudo das pulsações climáticas, por meio de várias expedições. (ibid, p. xiii)

Huntington foi condecorado com o rótulo "determinista", estreando-o, após a publicação de "The pulse of Asia", em $1907^{2}$,obra que apresentou um ponto de vista que rapidamente provocou reações em todo país. Martin observa que os críticos não leram o prefácio (como de praxe, também não leram o de Ellen Semple), no qual Huntington alertava que "O leitor deve examinar cuidadosamente estas páginas tendo em mente que ele está presenciando uma teoria em processo de construção". (ibid, p. xv), ou seja, Huntington avisa que está publicando uma teoria inacabada, e isso jamais foi anticientífico. Martin explica que os primeiros escritos de Huntington claramente denotam uma postura "ambientalista", pois havia uma busca contínua dos efeitos do ambiente sobre $\mathrm{o}$ indivíduo e sobre a sociedade humana. Note-se que o termo usado foi "ambientalista", termo que, às vezes, é usado não como sinônimo de "determinista ambiental radical", mas sim, de "determinista ambiental moderado", ou seja,

\footnotetext{
2 Assim, oito anos mais tarde, quando publicou "Climate and Civilization", já havia angariado uma platéia de ávidos críticos, todos usando as lentes deterministas que "adquiriram" pela leitura de "The Pulse of Asia"
} 
praticamente um "possibilista"3. Sua obra "The Pulse of Asia" foi lançada numa época em que poucos de seus contemporâneos reconheciam a validade da tese das pulsações climáticas na história. Após mandar um questionário para a Associação dos Geógrafos Americanos, para geólogos, para o comitê climático da Sociedade Ecológica Americana e para alguns meteorologistas, a aceitação foi generalizada, despertando também críticas severas.

Segundo Martin (1973), na obra "World Power and Evolution", Huntington exibe um interesse de rara heterogeneidade para um geógrafo de sua época. Foi um dos membros fundadores da "Associação dos Geógrafos Americanos", e contribuiu substancialmente com o "aparato" dos geógrafos. Foi um dos primeiros a insistir na validade das isopletas, a investigar efetivamente os ciclos, a insistir na medida matemática em detrimento de generalizações imprecisas e a usar extensivamente o coeficiente de correlação. Martin não opina sobre isso, mas Huntington parece ser o precursor, ou ao menos um dos, da Geografia Quantitativa. Foi autor do primeiro livro substancial a respeito dos princípios da Geografia Humana nos Estados Unidos, escreveu quatro livros, que permitiram a popularização da Geografia Econômica, e escreveu vários outros sobre princípios gerais da Geografia, sobre os efeitos do clima e acerca da natureza da mudança climática e de suas causas. Seus mapas e seus escritos foram extensivamente reproduzidos pelos seus colegas e seus livros didáticos disseminaram-se por todo território americano, em escolas de nível médio, em

3 Carvalho Jr (2011) realiza um estudo pormenorizado e abrangente do determinismo ambiental na história do pensamento geográfico e reforça a tese de que a dualidade determinismo versus possibilismo jamais existiu. universidades e em departamentos de Geografia, Antropologia, Sociologia, Economia, dentre outros. Prestava assessoria para as instituições de ensino, de modo a ajudá-las a eleger os livros didáticos a serem utilizados. Essas características indicam um geógrafo inovador e pioneiro, tanto em suas idéias, quanto em pesquisas científicas, e também um pensador preocupado com o ensino da Geografia.

Quanto à questão do livre-arbítrio, os escritos de Huntington mostram claramente que ele não negava ao homem a capacidade de fazer escolhas, e apontam na mesma direção do possibilismo e do probabilismo que duas décadas mais tarde seria sugerido por Spate:

No prefácio de "O Habitat Humano" (1927), Huntington escreveu: "O ambiente físico nunca impele o homem a fazer qualquer coisa, a compulsão reside em sua própria natureza. Mas o ambiente de fato diz que algumas condutas são permissíveis e que outras são impossíveis". Ao revisar a obra "Caráter nacional e os fatores na sua formação", de Ernest Barker (1927), Huntington revelou mais uma vez sua simpatia com o ponto de vista 'possibilista': "Os geógrafos estão finalmente vindo a reconhecer a tese central de Dr. Barker, que discute o ambiente físico." 'O ambiente não diz ao homem que ele deve fazer isso ou aquilo. Ele meramente diz 'aqui estão as possibilidades. Escolha qual você deseja. Ou escolha uma agora, e outra mais tarde.' Ele poderia talvez fazer muito bem em ir de alguma forma mais adiante, ao apontar que o ambiente limita as possibilidades de forma a mostrar ao homem que apenas algumas poucas possibilidades provarão serem lucrativas num certo estágio do progresso humano...Mais uma vez, ele volta-se para a idéia de que "a escolha do homem determina seu ambiente mais do que o ambiente determina sua escolha." (ibid, p.241).

Mais um exemplo de que a crítica vê apenas o que quer ver, apenas o que lhe 
convém e o que é mais fácil, é a publicação de um livro, seis anos após "The Human Habitat", chamado "Economic and Social Geography", de 1933. Segundo Martin (1973), nesse livro Huntington afirma que o ambiente geográfico meramente oferece ao homem oportunidades e que são seus desejos que vão determinar quais das várias oportunidades ele aceitará e quão longe ele irá ao usá-las. Contudo, Martin aponta que houve uma crítica sem a prévia leitura dos autores que julgavam "deterministas", e a leitura da obra de Huntington mostra que sua ponderação sobre as implicações filosóficas e intelectuais de sua obra provam que ele não era ingênuo e radical como seus críticos afirmavam.

Huntington afirma que é impossível falar de todos os assuntos num único livro e que os críticos, se não leram sua obra toda, não podem criticá-lo a ponto de afirmar que ele ignora a complexidade das relações por ele estabelecidas. Além disso, esses mesmos críticos não poderiam afirmar que Huntington advoga uma relação simplista entre natureza e sociedade.

Waswo (1989), sem se endereçar especificamente à crítica ao determinismo, elucida com clareza e síntese genial os motivos pelos quais tantos geógrafos têm sido mal interpretados ao longo da história da disciplina.

A falsificação emerge do esforço exigido para ler o texto, para o qual algum contexto é necessário. (...) Eles tomam 0 texto de maneira equivocada porque ignoram a linguagem e os conteúdos da disciplina, e são motivados apenas por modismos e ideologias benéficas aos seus interesses pessoais, e não pelo desejo de uma investigação desinteressada e metódica dos "fatos pretéritos". (WASWO, 1989, p.324)

Essa idéia coincide com a de Martin, que afirma que Huntington foi muito mal compreendido por aqueles que não tinham a capacidade e o interesse para entender $e$ apreciar sua obra. Dentre esse grupo de "ignorantes", encontravam-se principalmente geógrafos e historiadores, ao passo que dentre climatólogos e geólogos seus trabalhos eram amplamente aceitos. Parece simplista e infantil dizer isso, mas temos que aceitar, sem constrangimentos, que o motivo mais recorrente a impulsionar críticas desastradas é simplesmente não entender a obra ou constatar sua grandeza e ignorá-la por insegurança intelectual.

Spate (1968) é outro comentador cauteloso que aponta para a ingenuidade e fragilidade do conceito de Civilização de Huntington, mas reconhece que não há em sua obra uma indicação de que o clima é a causa da civilização.

Spate, corroborando a afirmação de outros comentadores, também vê em Huntington um esforço para compreender o papel de fatores culturais e institucionais.

Spate encerra sua pequena, mas ponderada, análise, afirmando que a pesquisa em ecologia humana $e$ em Geografia Médica na década de 60 deve muito a Huntington.

Chappel e Matley (1967) observam com astúcia que a obra de Huntington oferece um riquíssimo hall de conhecimentos para os estudantes se familiarizarem com a teoria das mudanças climáticas e com a relação clima/civilização. Também alertam para a existência de apenas um único trabalho extenso e exclusivo sobre as idéias de Huntington, trabalho cuja reveladora conclusão é a de que muitas das visões de Huntington sobre as mudanças climáticas ao longo da história permanecem surpreendentemente fortes, mesmo sob a luz de pesquisas recentes. 
Finalizando a análise da vida e obra do autor, extrai-se da análise minuciosa de Martin algumas características marcantes de Huntington, e que ajudam a entender os motivos pelos quais foi tão rotulado e simplificado 4 pelos críticos de sua época e pela crítica póstuma:

1. Foi o mais controverso geógrafo da primeira metade do século $X X$.

2. Foi o mais prolífico geógrafo, tendo produzido a obra mais extensa.

3. Suas obras foram as mais procuradas pelos editores.

4. Sua formação entendia-se por várias áreas das humanidades e das ciências naturais.

5. Conhecia os cinco continentes, engajandose em inúmeras expedições, principalmente para a Ásia Oriental e Oriente Médio.

6. Foi precursor de várias áreas do conhecimento e contribuiu para o incremento científico de áreas como a Paleoclimatologia, Geologia, Arqueologia, Climatologia, Bioclimatologia, Meteorologia, Geografia Humana e História.

7. Seus livros didáticos dominaram 0 mercado por algumas décadas.

\section{DISCUSSÃO E ANÁLISE DA OBRA "CIVILIZATION AND CLIMATE"}

Para se compreender a relevância das idéias de Huntington, é preciso expor e analisar alguns aspectos da obra "Civilization and Climate". Esta obra lida com diversos assuntos: raça e lugar; o homem branco nos trópicos; o efeito das estações; o efeito da umidade e da temperatura; trabalho e tempo

\footnotetext{
4 Somente um autor cujo pensamento e cujas idéias são ricas e complexas pode ser passível de severa simplificação, posto que o simples ou o rudimentar dificilmente pode ser simplificado a ponto de ser distorcido e empobrecido.
}

atmosférico; saúde e atmosfera; mortalidade, umidade e variabilidade; saúde e tempo; o clima ideal; a distribuição da civilização; vitalidade e educação nos Estados Unidos, as condições da civilização; a migração das zonas climáticas; a hipótese pulsatória e suas críticas, os centros migrantes das civilizações; América aborígene e Austrália moderna; a hipótese climática da civilização.

O prefácio da obra, assim como o das obras de Semple, é esclarecedor da capacidade autocrítica de Huntington, mas tal prefácio, ou não foi lido pelos críticos, ou foi ignorado por má-fé, pois as explicações são claras e totalmente plausíveis, o que deveria ter inibido críticas simplistas e distorcidas. Huntington explica que a idéia inicial era discutir todos os fatores, procurando dar o devido peso a cada um, contudo, pela grandeza da empreitada, pelas dificuldades inerentes, e também por sugestões de amigos, concentrou-se na hipótese climática, que era inexplorada (os predecessores apenas esbarraram no assunto). Também alerta os estudantes quanto à necessidade da leitura de obras prévias para que compreendam a hipótese climática dentro de um contexto mais amplo, o qual não caberia em uma única obra.

Nove anos mais tarde, já na terceira edição, Huntington escreve outro prefácio no qual explica que realizou radical revisão da obra, pois nesse tempo vários avanços na ciência foram feitos, o que fortaleceu a hipótese climática.

Na terceira edição, nota-se, então, uma maior ênfase no fator hereditariedade, e um capítulo totalmente novo, no qual Huntington se defende da crítica direcionada à sua hipótese climática pulsatória.

No capítulo 1, Huntington esclarece seus objetivos, expõe suas metodologias, e reconhece algumas limitações e armadilhas 
epistemológicas, quase sempre acompanhadas de ponderação e de autocrítica.

Contudo, a primeira frase da obra, "The races of the earth are like trees" (As raças da terra são como árvores). (HUNTINGTON, 1939, p.1), já levanta as sobrancelhas daqueles que implicam insistentemente com a analogia orgância que ainda hoje domina, não sem razão, implícita ou explicitamente, o discurso da maioria dos pesquisadores nas ciências humanas, sem que estes sejam jogados na valeta do evolucionismo, do darwinismo social e do determinismo ${ }^{5}$.

Para ele, a hereditariedade é apenas um dos fatores no desenvolvimento da civilização. Governo, educação, religião, ocupação, costumes, instituições e, nos dizeres dos antropólogos, a cultura herdada, formam um segundo grande grupo de influências sociais cujo poder parece quase imensurável.

Huntington afirma que o clima não é o fator mais importante, mas é o mais "fundamental", no sentido de que vem primeiro e influencia outros fatores com mais força do que é por eles influenciado, além de prover alimentos e variados recursos vitais aos homens:

É fundamental devido a sua vital influência sobre a quantidade e a qualidade não apenas da comida do homem, mas da maior parte dos outros recursos; possui um grande papel em determinar a distribuição e a virulência de parasitas que causam a maioria das doenças; e por meio de seus efeitos sobre as ocupações humanas, modos de vida, hábitos, constitui-se em um dos principais

\footnotetext{
${ }^{5}$ Nenhuma dessas três complexas teorias tem sido apropriadamente e justamente criticadas, salvo raras exceções. As críticas em geral tendem a reduzí-las a uma versão estereotipada, e acabam por criticar o rótulo que criaram, e não a teoria em si, fato que para Bordieu é lamentável e muito recorrente nas ciências humanas.
}

determinantes da cultura. Por outro lado, nem comida, nem doenças e nem cultura tem qualquer efeito apreciável sobre o clima, apesar de eles poderem modificar sua influência. Assim, o clima tem um efeito direto sobre a saúde além de exercer influência indireta por meio da comida, das doenças e do modo de vida. Apesar do clima não ser mais importante do que outros fatores em determinar 0 relativo grau de progresso em diferentes partes do mundo, é mais fundamental no sentido de não ser o resultado dos outros fatores, mas sim, sua causa. (ibid, p.3)

Huntington faz uma distinção fundamental entre três tipos de influências climáticas:

Ao estudar o clima, é essencial fazer uma distinção entre três tipos de influência. Em primeiro lugar, o clima tem um efeito direto sobre a atividade e a saúde dos homens. Em segundo lugar, ele tem um forte e imediato efeito indireto pela alimentação e demais recursos naturais, por meio de parasitas, e através do modo de vida. Em terceiro lugar, pela combinação de seus efeitos diretos e indiretos no passado, tem sido um forte fator, alguns diriam, o mais forte, na ocorrência de migrações, mistura racial e seleção natural; e isso pode ter algo a ver com a produção de variações chamadas pelos biólogos de mutações. Dessa forma, o clima tem exercido um efeito poderoso sobre a hereditariedade. (id)

Os primeiro e o segundo tipos de influências foram menos contestados, pois são mais mensuráveis, há mais evidências, e tem o respaldo de ciências mais "respeitáveis", como a medicina. Já o terceiro, mais complexo, adentra o universo impreciso, incerto e abrangente das civilizações, da história humana, dos movimentos migratórios e lida com questões complexas e polêmicas como raça e seleção natural, portanto geraram desconfiança da comunidade científica. Entram no cômputo da desconfiança e do descrédito alguns outros 
quesitos, como as tendências dos historiadores em apresentar cada um a sua reconstrução-fantasia das civilizações passadas, as incertezas sobre os verdadeiros climas pretéritos, e a resistência das ciências humanas em lidar com as limitações naturais que ameaçam a soberania do homem ilustrado das luzes e dos lustres da razão e da "liberté".

Huntington (1939) reconhece que há dois grandes grupos de fatos aparentemente contraditórios. Ele afirma que estamos conscientes de que somos estimulados ou deprimidos por condições climáticas, e de que sabemos que ao irmos para o norte ou para o sul a distribuição das civilizações está geralmente em harmonia com o que nós esperamos em função de nossas próprias experiências climáticas. Não obstante, até mesmo em nossos dias (ou seja, na década de 10$)$, regiões que se situam na mesma latitude e aparentemente possuem climas igualmente estimulantes, diferem marcadamente em seu grau de civilização ${ }^{6}$.

Quando comparamos o passado com o presente, encontramos a mesma contradição, ainda mais marcada. Daí nossa confusão. Pela experiência pessoal, sabemos que os efeitos diretos do clima são de uma importância tremenda. Contudo, muitos fatos parecem indicar que esta importância é menor do que nossas observações nos levariam a antecipar. Essa contradição é explicada com o seguinte texto:

As razões para essa atitude incerta pode ser facilmente descoberta. As coisas por nós chamadas de 'fatos', são freqüentemente não muito bem estabelecidas. Apesar de nós acreditarmos na influência do clima, sabemos muito pouco dos elementos

\footnotetext{
${ }^{6}$ O que Huntington considerava "civilizado" é que se constitui no maior problema de sua tese.
}

climáticos que são particularmente estimulantes ou deprimentes. O quanto sabemos nós acerca da importância relativa da pressão barométrica, dos ventos, da temperatura, da umidade? E sobre os efeitos comparativos dos climas da Inglaterra e do sudeste da Rússia? Além disso, estamos longe de saber quais tipos quais tipos de clima prevaleceram no Egito, Grécia ou Mesopotâmia quando eles se tornaram proeminentes. Muitas autoridades no assunto tem asseverado que o clima daquelas regiões eram os mesmos há dois ou três mil anos. Esta visão tem perdido espaço, mas aqueles que acreditam numa mudança do clima não estão certos de sua natureza. Não há um consenso na direção da crença de que a mudança do clima tenha produzido uma influência importante sobre os particulares elementos climáticos que são mais estimulantes para o sistema humano. (ibid, p.5).

Esse reconhecimento de Huntington, sobre nossa limitação e ignorância, não foi observado pela crítica em geral. Assim, um dos equívocos mais comuns entre os críticos é justamente o de não enfatizarem que Huntington reconhecia essas limitações e exceções mencionadas. A obra de Huntington, quando analisada mais de perto, mostra um geógrafo que foi capaz de dar uma importante contribuição para a filosofia ambiental.

Por outro lado, enquanto os críticos deliciavam-se na caçamba determinista Huntingtoniana, alguns equívocos menores, porém de certa relevância, não eram sequer notados. O autor, ao comparar o clima de regiões específicas, afirma que a Mongólia e o Illinois, apesar de estarem na mesma latitude e terem a mesma temperatura média anual, diferem enormemente em civilização. Contudo, o que Huntington pensa ser uma exceção à sua regra, pode ser mais bem usada como confirmação! A Mongólia possui um clima distinto em muitos aspectos quando comparado ao clima da região dos grandes 
lagos. É mais continental, com menor influência oceânica, mais frio, tanto no inverno, quanto no verão, quando o fator altitude impede o calor extremo, ao passo que em Illinois pode chegar a 40 graus e com elevada umidade. Ou seja, a Mongólia possui clima semi-árido ao norte e árido na metade sul. Predominam as pradarias de altitude, amplas, e margeadas por montanhas em sua parte sul e oeste, enquanto Illinois fica numa planície, e sofre o efeito da maritimidade dos grandes lagos. Illinois também é afetado por ciclogênes mais freqüentes e intensas e só esse fato, separadamente, já indicaria uma grande diferença em relação à relativa estabilidade dos tipos de tempo no planalto ultracontinental da Mongólia. Ou seja, Huntington, um pouco por descuido, e principalmente pelos parcos conhecimentos climáticos da época, não atentou para as profundas diferenças entre os climas da Mongólia e do Illinois. É com base nos conhecimentos atuais que as obras dos deterministas do passado podem ser contestadas cientificamente com bases mais sólidas, e não em função de "correntesideológicas", medos do bicho-papão-clima, do boitatá-solo, da mula-sem-cabeça-dalocalização-e-distância; e implicâncias teimosas $^{7}$ com o darwinismo, neolamarckismo, organicismo, positivismo ou qualquer outro dentre os vários "ismos" fantasmagóricos da cripta acadêmica.

Huntington afirma que seu livro foi escrito com base em duas linhas de investigação que, combinadas, pretendem explicar ao menos parcialmente algumas das

\footnotetext{
7 Segundo CARVALHO JR (2011), a psicanálise possui teorias bastante plausíveis para explicar a forte oposição de pensadores e intelectuais das ciências humanas em relação às forças naturais, determinações e influências da natureza sobre a sociedade.
}

contradições que têm se mostrado um complicado quebra-cabeça:

Em primeiro lugar, um estudo prolongado das variações climáticas presentes e passadas levou à conclusão de que o clima do passado era diferente do clima do presente. A segunda linha de investigação que originalmente conduziu à escrita deste livro foi o estudo das condições climáticas sob a qual pessoas de raças européias são capazes de trabalhar com máxima eficiência e ter a melhor saúde. Esta investigação levou a conclusão de que o princípio do optimum climático aplica-se tanto ao homem quanto à plantas e animais. (ibid, p.5-6).

Huntington reconhece que a distribuição das civilizações é tão complexa, e envolve tantos fatores, que ela deve ser explicada, no mínimo, pela combinação do efeito direto do clima sobre o homem, com a seleção natural realizada pelas mudanças climáticas, daí a importância de se estudar as pulsações climáticas do passado para entender de que maneira os climas mutantes exerceram influências no sentido de favorecer a permanência ou a migração dos povos, e de retardar ou acelerar seu desenvolvimento sócio-econômico. Esta hipótese climática é atual e há vários núcleos de pesquisa procurando compreender o declínio de povos pré-colombianos. Até mesmo os que acreditam no aquecimento global não podem ser incoerentes em negar a teoria de Huntington, uma vez que postulam uma mudança brutal dos modos de vida, da economia e dos centros de poder com ursos polares afundando nas profundezas do mar "ex-glacial ártico".

Ele explica que uma grande parte do raciocínio de seu livro gira em torno da hipótese climática pulsatória nos tempos históricos. 
Isto levou ao que eu chamo de "hipótese pulsatória", que forneceu o nome para "The Pulse of Asia". De acordo com essa hipótese, apesar do passado histórico e pré-histórico naquelas regiões particulares ter sido geralmente mais úmido que no presente, a mudança do úmido para o seco tem ocorrido irregularmente $e$ em grandes ondas. Até mesmo no início dos tempos históricos certos séculos foram aparentemente mais secos do que hoje, enquanto que outros anos não tão remotos foram úmidos. (ibid, p.7-8).

Após alcançar a conclusão de que as mudanças climáticas pulsatórias ocorreram de fato ao longo da história, e que diferiram em tipos de uma região para outra, o próximo passo de Huntington foi estudar o mecanismo e a causa das supostas mudanças. Várias linhas de evidências também indicaram que as pulsações climáticas consistiam na migração das zonas climáticas da terra ou ao menos na migração de áreas de tempestades ciclônicas alternadamente para perto e para longe da linha do equador. Após constatar tudo isso, aí sim Huntington partiu para a próxima fase de investigação, nomeadamente, o estudo do efeito real dos presentes climas sobre a atividade humana e a saúde dos homens:

Isto é importante porque alguns críticos têm suposto que eu super enfatizei a importância das mudanças climáticas, ou até mesmo que eu formei uma teoria sobre elas com o propósito de disseminar uma idéia pré-concebida de que as diferenças climáticas entre os lugares são a principal causa da presente distribuição do progresso humano. (ibid, p.100.)

Huntington explica que sua intenção

foi mal-compreendida, pois:

Pelo contrário, até o momento, meu raciocínio tem sido de alguma forma o seguinte: Se mudanças climáticas têm ocorrido durante tempos históricos, elas devem ter tido algum efeito econômico porque tais mudanças alteram a capacidade de uma região em suportar população. As mudanças econômicas, por sua vez, devem ter levado a distúrbios políticos e migração. (ibid, p.10-11).

Até mesmo Kropotkin, que eu inadvertidamente imaginava como apenas um ideólogo revolucionário interessado em política, estudou, segundo Huntington, o papel do clima sobre as invasões bárbaras na Europa.

Huntington assume que se impressionou ao ver que cada civilização que atingia seu ápice, possuía nessa época um clima que se aproximava de certas condições, que ele define posteriormente como sendo as do clima temperado oceânico. Ou seja, o momento de máxima aproximação de um clima qualquer com o clima temperado oceânico (controversamente o próprio clima da terra natal de Huntingon, New England) parecia coincidir com o desenvolvimento máximo da civilização que nele habitava.

Enquanto esses efeitos econômicos e políticos das mudanças climáticas estavam sendo estudados, eu me tornei mais e mais impressionado pelo fato de que quando um país atingia o seu mais alto nível de civilização, parece que de um modo geral usufruía de um clima que se aproximava mais intimamente do que hoje, a certas condições bem definidas. Essas condições pareciam lembrar aquelas que agora prevalecem na maior parte das regiões nas quais o nível de civilização é mais alto. A despeito de variações acentuadas, a tendência geral durante períodos de alta civilização tem sido, aparentemente, na direção de invernos suaves e de verões que, ainda que mornos ou quentes por vários meses, são geralmente interrompidos por tempestades ou ao menos por ventos que produzem mudanças freqüentes de temperatura. (ibid, p.12).

Antes desses estudos e dessas conclusões parciais, Huntington acreditava apenas nos fatores políticos e econômicos: "Até agora, eu 
não vi espaço para se apelar a nada que não sejam os fatores econômicos e políticos, na explicação da aparente conexão entre civilização e clima." (ibid p.12). Segue afirmando que o clima exerce efeitos diretos sobre a economia e sobre a saúde:

$\mathrm{Na}$ verdade, agora parece provável que através de seu efeito em bactérias, no suprimento de água, no lugar de alimentação de insetos, na qualidade dos alimentos, e talvez de outros modos, as mudanças climáticas podem exercer tantos efeitos quanto por meio de canais econômicos mais diretos. (ibid, p.12-13)

Sobre a crença em voga na época e suportada por Huntington, de que as melhores áreas para o desenvolvimento da civilização são aquelas de maior atividade ciclônica (extra-tropicais), ele cita Kullmer: "Ele disseminou a idéia de que as mudanças barométricas que são a causa primeira das tempestades, ou talvez algum fenômeno elétrico que as acompanham, podem produzir um estímulo que tenha muito a ver com o avanço das civilizações." (ibid, p.13). Como Kullner não apresentou provas, Huntington partiu corajosamente para a busca dessas evidências.

Huntington reconhece as limitações metodológicas para provar essa relação civilização-ciclogênese, descreve as formas ideais, e explica a metodologia que foi possível. Ele acompanhou a produtividade de milhares de trabalhadores, divididos em quatro grupos, selecionou várias cidades desde Connecticut até a Flórida, e utilizou dados do ano todo, dia após dia, e todos os resultados foram comparados com os dados meteorológicos do dia. A conclusão foi a de que a pressão era pouco importante, a umidade moderadamente relevante, ficando a maior influência por conta da temperatura, cujo optimum foi mais elevado do que se esperava. A condição ideal para a produtividade e bem-estar foi descrita da seguinte forma: "A condição ideal, ou optimum, parecia ser invernos brandos com algumas geadas, verões brandos com temperatura raramente acima de $75^{\circ} \mathrm{F}$ e uma constante sucessão de tempestades suaves e moderadas mudanças de tempo de um dia para o outro." (ibid, p.15). Atualmente, a bioclimatologia reconhece a importância e plausibilidade da questão do optimum climático para os seres humanos, mas há um tabu, não sem alguma razão (medo do rótulo de "determinista"), em associá-lo à produção física do ser humano, e mais ainda, à produção intelectual, reconhecidamente afetada, por sua vez, pelas condições físicas.

Após esse estudo dos trabalhadores nos Eua, Huntington construiu um mapa mostrando como a energia humana seria distribuída pelo mundo se (aqui está um dos problemas) todos os habitantes do planeta fossem influenciados da mesma forma que os 15 mil contemplados por seu estudo. Ou seja, países com clima muito divergente do optimum climático observado nos Eua teriam uma população de menor energia e menor bem-estar. Huntington notou que o mapa coincidia em grande parte com o mapa da distribuição da civilização na época. Este mapa foi baseado em 50 geógrafos e "widely informed men" pelos quatro cantos do planeta. Não obstante, esse mapa das civilizações sofreu mais críticas do que o mapa climático. Huntington concluiu que as mudanças climáticas de fato ajudaram os países a declinar ou a atingir seu ápice, pois havia uma coincidência entre o predomínio de tempos dentro do optimum climático e o período em que essas civilizações mais 
floresceram. A lista de objeções que se pode fazer a esses ousados estudos é estarrecedora, contudo, isso não significa que podemos invalidar a contribuição preliminar ao estudo da relação clima-civilização, nem o esforço hercúleo de Huntington em enriquecer uma área de estudos que ainda hoje engatinha.

Huntington formula a questão central para a questão do optimum climático, usando o exemplo do Egito, e reconhece que o nível tecnológico influi no patamar do optimum climático, que pode ser mais quente que 0 verificado em sua pesquisa na costa leste dos EUA.

Assim, reconhece que para se estabelecer qual é o optimum climático de uma civilização, é necessário saber seu estágio de desenvolvimento e talvez também levar em conta diferenças raciais.

Huntington afirma que seu trabalho foi mais aceito, sem preconceitos e à espera de maiores avanços científicos, pela comunidade não-científica, e por geólogos, arqueólogos e geógrafos da área geológica, pois os demais geógrafos ofereceram cega resistência, atitude que a história da ciência tem mostrado como sendo habitual e esperada, sempre que se fala em teorias inusitadas e complexas.

Por outro lado, economistas, sociólogos, antropólogos e principalmente historiadores, raramente confiaram nas evidências provenientes das ciências naturais. A opinião do "politburo" foi modelada por duas suposições amplamente aceitas na época: a de que a uniformidade climática na escala temporal é uma condição natural, que Huntington considera absurda em face das crescentes evidências das pesquisas glaciais; e a crença na maior pertinência e confiabilidade dos registros escritos e das estatísticas em detrimento das evidências geológicas.

Huntington resume essa querela entre evidências históricas e registros escritos versus evidências geológicas, climáticas e glaciais, explicando que a história não pode ser devidamente escrita sem que sua base física seja completamente compreendida: "A história nunca poderá ser escrita corretamente até que sua base física seja completamente compreendida, e até que seja reconhecido que condições econômicas e que a saúde e energia humanas variam de tempos em tempos tanto quanto variam as condições políticas religiosas e de personalidade." (ibid, p.20).

Ele também explica que manteve a ênfase nas influências diretas do clima sobre a fisiologia humana e sobre a saúde, por meio da alimentação e dos efeitos sobre insetos e microorganismos:

Mudanças climáticas parecem também ter um efeito direto sobre a atividade física humana, um ponto de vista que dominou a primeira edição deste livro. É óbvio que através de seu efeito sobre alimentos, insetos, bactérias e sobre o próprio poder de resistência, as mudanças climáticas devem exercer uma grande influência sobre a saúde. (ibid, p.28).

Ou seja, para Huntington, o clima predispõe à doença, mas não é sua causa, idéia corrente entre os cientistas da atualidade.

Contrariando a crítica, Huntington afirma que a influência do clima não se dá apenas diretamente, de forma mágica, sem intermediários, mas sim, por meio das condições econômicas e políticas, pela guerra e migração, recursos naturais e alimentos, energia e saúde, e através da seleção natural e das mutações, este último fator sendo o mais tardiamente notado por Huntingon.

Apenas com todos esses fatores em vista é possível, para Huntington, realizar 
uma verdadeira filosofia da história. Contudo, reconhece que seu estudo, apesar de em sua terceira edição trazer uma visão mais abrangente e profunda que seus predecessores, não tem a pretensão de esgotar todos os fatores, mas apenas aquele que concerne os efeitos diretos do clima sobre a energia e a saúde humanas.

No capítulo dois, que trata de debater as influências da raça e do lugar, Huntington demonstra uma preocupação com a possibilidade de se separar os efeitos diretos do clima daqueles provenientes da hereditariedade: "O principal problema que nos ameaça é a dificuldade em separar os efeitos diretos do clima daqueles provenientes da hereditariedade, a despeito da questão que indaga sobre a possibilidade da própria hereditariedade ter sido influenciada por climas do passado." (ibid, P.30). Sua busca pela resposta emaranhouse pelo abismo polêmico das supostas diferenças raciais. Sobre os brancos nas Bahamas se refere de modo a mostrar sua crença na degeneração dos brancos. Sua teoria da degeneração dos brancos nos trópicos não é simplista como imaginam os críticos, pois ela considera vários outros fatores para explicar a extinção/fuga dos brancos dos trópicos, como a falta de descanso e o temperamento nervoso.

No capítulo dois e em outros capítulos Huntington busca entender as razões pelas quais o sul dos EUA prosperou menos do que o norte e apesar de reconhecer timidamente o fator racial, apontou para as diferenças de clima como cruciais. São vários os intelectuais, como Caio Prado Junior (2000) e Gilberto Freyre (2000), que reconhecem o clima tropical como fundamental na explicação do que foi o Brasil colonial e do que viria a ser o Brasil após esse período. Huntington não foi o primeiro nem o último a desconfiar que o clima "enervante" dos trópicos tinha seu papel garantido no amplo rol de fatores que compõem o mosaico explicativo do desenvolvimento das nações.

Huntington, apesar de acreditar em certas vantagens intelectuais de umas raças em relação a outras, não era um conservador retrógrado que pretendia preservar a "pureza" racial, pelo contrário, é adepto da teoria da miscigenação benéfica, pois acreditava que não seria irracional pensar num mundo que pudesse vir a constituir no futuro uma raça única, fruto de todas as boas qualidades de cada uma das raças, unindo o melhor de cada uma delas "formando uma sociedade inimaginavelmente superior e distinta de tudo que existe e existirá" (ibid, p.55)

No capítulo três, "The white man in the tropics", Huntington inicia o texto com surpreendente afirmação "nostradâmica", a de que os trópicos contém as searas de desenvolvimento futuro mais ricas $e$ convidativas:
Vamos falar agora da zona tórrida, que contém os mais ricos e convidativos campos de desenvolvimento futuro. Vamos indagar sobre o efeito dessas regiões sobre os europeus que tentam nelas viver de maneira permanente. 0 isolamento das regiões tropicais, a falta de facilidades nos transportes, e as grandes dificuldades da agricultura serão indubitavelmente superados, mas isso tudo não vai resolver definitivamente o problema. Dois grandes obstáculos ainda permanecerão - os habitantes nativos, assim como a mente e o corpo dos próprios homens brancos. (ibid, p.56).

Sobre o efeito estimulante do clima temperado afirma que tanto o clima quanto o ambiente social são responsáveis pela mudança na eficiência dos povos recémchegados: "Sem dúvida, a mudança no negro é devida ao novo ambiente social, tanto 
quanto ao novo ambiente físico, e muitas autoridades acreditam que a mudança social é a mais importante." (ibid, p.57-58)

Huntington finaliza esse capítulo reconhecendo que diversos males verificados entre os brancos nos trópicos têm múltiplas causas, e não apenas o clima:

Em todos os males que acabaram de ser mencionados - preguiça, raiva, bebedeira e imoralidade, causas sociais undubitavelmente tem um importante papel. Juntamente com o aspecto social da questão, todavia, sem ser mais ou menos importante, vai o aspecto físico. Temos que descobrir até que ponto as condições físicas estimulam ou inibem 0 desenvolvimento de um caráter forte. Esse é o propósito dos capítulos que se seguem. (ibid, p.75)

O capítulo quatro trata do efeito das estações, assim como os capítulos posteriores e será abordado de maneira sintética, trazendo algumas afirmações gerais e "conclusivas" de Huntington, dada a escassez de espaço. Mais uma vez, reitero que meu objetivo não é fazer uma releitura abrangente, detalhada e inovadora de Huntington, mas apenas indicar alguns traços que não foram notados pela crítica, ou que foram mal compreendidos. Logo no início deste capítulo, Huntington reconhece que fez comparações que levaram a generalizações que datam de Aristóteles, Montesquieu e Ratzel.

Sobre o efeito das estações e tipos de tempo ${ }^{8}$, apela para a impressão popular (que não é a priori sempre inválida), e solicita:

Novamente, pergunte a alguns amigos se eles trabalham melhor em dias ensolarados ou nublados. A maioria vai provavelmente responder que o primeiro dia ensolarado após uma tempestade é o melhor. Um

\footnotetext{
${ }^{8}$ Esta idéia é a mesma que Hipócrates chamava de "Changes of the seasons", ou seja, acentuada dinâmica atmosfera, com variados tipos de tempos que mudam constantemente, características essas que grande parte da literatura acerca das influências climáticas afirma ser ideal para o bemestar e para o estimulo físico e mental das pessoas.
}

pequeno número vai pensar com mais cuidado sobre a questão, para então dizer que após uma tempestade a limpeza do ar e a luminosidade do sol são certamente inspiradores, mas que trabalham melhor quando chove. Esta divergência de opiniões é devida grandemente ao fato de que os efeitos climáticos são de dois tipos, psicológico e fisiológico. Nós sempre estamos conscientes do primeiro tipo, mas geralmente estamos inconscientes do segundo tipo. (ibid, p.77).

Huntington mostra a ambivalência dos efeitos dos tempos anticiclonais, pois esses dias claros, suaves e coloridos ajudariam a trabalhar com mais eficiência, ou nos distrairia na direção da beleza proporcionada?

Huntington afirma que conhecemos melhor, pela experiência, os efeitos psíquicos do clima, enquanto os efeitos físicos permanecem largamente desconhecidos:

As questões que acabaram de ser feitas e as possibilidades que foram sugeridas mostram quão indefinidas são nossas idéias dos efeitos do clima. Nós compreendemos seus efeitos psicológicos razoavelmente bem. Nós sabemos muito pouco sobre seus efeitos fisiológicos, todavia, exceto quando eles são extremos ou incomuns, ou quando as pessoas estão doentes ou sob alguma outra condição patológica. Precisamos determinar como as pessoas ordinárias são influenciadas por condições ordinárias de tempo. (ibid, p.80)

Huntington finaliza o capítulo

resumindo os resultados da seguinte forma:

Resumindo a questão, vimos que os resultados das investigações na Dinamarca, Japão. Connecticut, Pennsylvania, New York, Maryland, as Carolinas, Georgia e Flórida estão em harmonia. Todos eles mostram que, com exceção da Flórida, nem o inverno, nem o verão é a estação favorita. Ambas as atividades, físicas ou mentais, atingem um máximo pronunciado na primavera e no outono, com um mínimo no meio do 
inverno e no meio do verão. A consistência de nossos resultados é de grande relevância. Conduz à crença de que em todas as partes do mundo o clima exerce uma influência que pode ser prontamente medida, e que pode ser sujeita à análise estatística [questionável, mesmo para os padrões científicos de hoje]. Justifica que continuemos com segurança a afirmar exatamente quais efeitos são produzidos por cada um dos elementos climáticos, tais como temperatura, umidade e pressão. (ibid, p.108)

No capítulo cinco, sobre os efeitos da umidade e da temperatura, Huntington se mostra um dos pioneiros no estudo de microclimas urbanos em áreas construídas, como casas e fábricas.

Um terceiro fator a ser considerado a essa altura, é a umidade relativa da atmosfera. Uma distinção clara deve ser feita entre a umidade externa e aquela que prevalece em ambientes fechados. Médicos, estudantes de administração, superintendentes de escolas, e muitas outras pessoas têm repetidamente discutido os supostos efeitos nocivos do ar seco dentro dos edifícios durante o inverno. (ibid, p.111)

Apesar de Huntington basear-se às vezes em médias, reconhecia a importância essencial da dinâmica climática, das mudanças bruscas do tempo e da marcha das estações em termos de atrasos e alterações dos padrões, assim como Hipócrates também já era ciente disso.

Huntington conclui esse capítulo alertando para a diferença do optimum climático verificado entre baixas e altas formas de vida, e para a diferença entre as leis naturais em termos de sua aplicação e de seus princípios:

Em geral, as formas inferiores de vida e de atividade parecem alcançar seu optimum em temperaturas mais altas do que os tipos mais avançados e as funções mais ligadas a mente. O pensamento biológico aponta para a conclusão de que as mesmas leis se aplicam a todas as formas de vida. Elas diferem em aplicação, mas não em princípio. A lei da temperatura ótima aparentemente controla os fenômenos da vida desde as mais simples atividades de um protoplasma até as atividades mais sofisticadas do intelecto humano. (ibid, p.135)

No capítulo seis fala da relação entre trabalho e tipos de tempo, concentrando-se nos efeitos das tempestades ciclônicas e da variação dos tipos de tempo.

Huntington conclui seu trabalho listando quatro tipos de clima, em ordem crescente de "qualidade" para o trabalho humano e seu bem-estar. O primeiro é o clima monótono, sem estações marcadas e com excessiva constância dos parâmetros atmosféricos; o segundo refere-se ao clima de excessiva variação dos tipos de tempo, que levariam as pessoas à exaustão pelo excesso de estímulos; o terceiro, seria o clima com contrastes entre as estações, mas que se caracterizam por tipos de tempo severos e excessivamente duradouros, o quarto e mais benéfico tipo, seria o clima com marcadas diferenças entre as estações, mas não suficiente para criar tensão nervosa, e que possuam frequentes tempestades, mas em menor número que o segundo tipo de tempo.

No capítulo sete, saúde e atmosfera, realiza estudos sobre vários aspectos, como a relação entre a temperatura do corpo e os fenômenos circulatórios; taxas de respiração e temperatura, eficiência mental e conforto, influências da umidade atmosférica, trabalho físico, suscetibilidade à doença, condições ideais de ventilação, etc. Huntington, ao se dedicar ao estudo dos efeitos do "ar quimicamente viciado" sobre os homens, em termos de estado fisiológico, conforto e 
eficiência, mostra-se um pioneiro no estudo dos efeitos da poluição sobre a saúde.

No capítulo oito, estuda a mortalidade em relação à umidade e à variabilidade dos parâmetros atmosféricos, como temperatura e umidade. Variabilidade não é um conceito tão recente quanto sugerem alguns climatólogos da linha dinâmica.

Sobre o capítulo nove afirma que:

Este capítulo lida com duas investigações da relação entre saúde e tempo. Elas me parecem formar a mais conclusiva evidência já disponível sobre essa relação, porque os vários elementos do clima estão mais claramente separados do que na maioria dos casos, e porque não há risco de confundir os efeitos de diferentes estações. A primeira investigação pertence ao tempo analisado diariamente, e é de longe a mais abrangente e extensa a usar dados diários. (...) Os resultados a respeito da temperatura média e mudanças de temperatura parecem ser bastante conclusivos, mas são inconclusivos aqueles referentes à umidade relativa. (ibid, p.194)

Após tratar especialmente do "clima ideal" no capítulo dez, Huntington trata da polêmica relação entre civilização e clima, que se distribui por temas, do capítulo 11 ao 18. Já foram discutidas as principais características dessa teoria, então se optou por trazer apenas alguns trechos dessa parte do livro, até mesmo porque esse assunto, 0 mais interessante da obra, merece um tratamento à parte, em comparação, no mínimo, com as obras de Semple, Ratzel, Thomas, Buckle e Toynbee, pois todos eles lidaram com a relação clima-civilização e serviriam de interessante contexto para a análise das teorias climáticas de Huntington.

Sobre a relação entre clima e civilização, Huntington reconhece que as diferenças entre países de mesma latitude podem ser tão pronunciadas quanto as diferenças verificadas entre os trópicos e as zonas temperadas, pois as variações diárias podem ser mais importantes do que 0 suposto.

Huntington também alerta que sua hipótese da pulsação climática não pode ser vista apenas pelo prisma da mudança de temperatura. Ou seja, a variação de chuvas e de tempestades é mais importante do que a variação da temperatura para se explicar o efeito das mudanças climáticas na migração das civilizações.

Sobre o Brasil, Huntington faz apenas um comentário, e reconhece que os "males" dos trópicos serão superados não apenas pelos estrangeiros, como pelos nativos mais inteligentes.

Contra o fatalismo equivocadamente associado aos deterministas, Huntington esclarece que:

Por enquanto, é suficiente ver que a hipótese do clima enquanto uma condição para a civilização está longe de ser deprimente ou triste. Ela sustenta que há esperança para os habitantes das regiões mais favorecidas da zona temperada melhorarem sua condição de vida. Ela sustenta mais esperança ainda de que as pessoas das partes menos favorecidas da zona temperada e da zona subtropical possam melhorar sua vida. (ibid, p.270)

Em Huntingon também não cabe o suposto preconceito dos "deterministas" contra o solo dos trópicos e das pragas e moléstias várias que "impedem" ou dificultam a agricultura: "Se os fazendeiros dos trópicos fossem tão eficientes quanto os da zona temperada, o trabalho de um homem produziria de duas a três vezes mais do que nos EUA ou na Europa. (ibid, p.280). Assim, Huntington pressagiou o que está em vias de acontecer. Ele também concedeu aos homens plenos poderes de aumentar sua eficácia e 
sua energia nas áreas tropicais, assim como em geral, nunca deixou de atribuir ao homem uma liberdade que equivale, muito provavelmente, à que foi reclamada por aqueles autores franceses rotulados de "possibilistas".

Huntington finaliza "Civilization and Climate" afirmando que "Se nossa hipótese for verdadeira, o homem é mais intimamente dependente da natureza do que ele pensa. Contudo, dar-se conta dessa limitação humana é o primeiro passo na direção da liberdade." (ibid, p.411) Trata-se de uma afirmação cuja sabedoria e humildade é estarrecedora, pois se trata de uma verdade que, se negada, nos coloca em risco de afundarmos nossa própria civilização atual, sob os auspícios de uma ciência arrogante e de uma filosofia pretensiosa.

Martin, em seu artigo "Civilization and Climate revisited", traz um apanhado geral das resenhas que se seguiram à publicação desse livro, e alguns comentários elogiosos a Huntington podem ser vistos no trecho abaixo:

Ao fazer grandes generalizações, o autor fala com cautela... A principais hipóteses em "Civilização e clima" são de uma importância inquestionável. Elas parecem apontar na direção de verdades de grande relevância...contêm inferências e deduções que são oferecidas como tentadoras, mas não definitivas. Trata-se de um livro muito original e estimulante. Pode abrir novas e frutíferas áreas de pesquisa; e suas conclusões possuem uma significância prática que ajuda acertadamente o cientista especulativo nas suas mais árduas tarefas: a tarefa de estimular a imaginação enquanto permanece dentro dos limites da credibilidade. Por essas qualidades, Huntington merece nosso respeito e admiração. Eu posso dizer, honestamente, que nenhum outro livro em uma década, e talvez apenas alguns poucos livros em toda minha carreira, me influenciaram tão profundamente como "Civilização e clima". (MARTIN, 1974, p.11)

Martin observa um fato peculiar em relação à crítica a Huntington:

A apreciação feita pela crítica, sobre Huntington, no início deste século, contrasta acentuadamente com numerosas críticas póstumas e distorcidas que o rotulavam de "determinista". Costumou-se esquecer que o real significado da palavra determinismo (ambiental) jaz na intersecção de certo tempo e certo espaço, e que é apenas nela que se pode dizer que algo ou alguém é "condicionado" (environed). (id)

Assim, a crítica à obra "Civilization and climate" foi ficando mais negativa $e$ rotulante à medida que passava o tempo, ou seja, na proporção em que iam se disseminando suas idéias na forma de "telefone-sem-fio". Meio século depois da publicação, as críticas eram as mais rasas possíveis, e o real entendimento de sua obra, mínimo.

A obra "Civilization and climate" também foi alvo da atenção médica:

Seus resultados foram bastante procurados pela medicina dos EUA, ele publicou seus achados em revistas médicas, recebeu um prêmio da "National Anesthesia Research" por seus méritos como pesquisador, além de ter sido muito valorizado por bombeiros e pelo pessoal qualificado na área de aquecimento, além de diretores de escola, todos eles interessados no tema "saúde e clima". (ibid, p.13-14)

\section{O próprio Martin sustenta a}

importância dessa obra monumental:

As idéias centrais contidas nessa obra, apesar de freqüentemente negadas, merecem uma investigação mais sustentada e séria, que faça justiça a Huntington. Essas idéias estão muito distantes do rótulo 
determinista dado a Huntington por críticos que sequer se importavam em soletrar seu nome corretamente. (ibid, p.10-11).

\section{CONSIDERAÇÕES FINAIS}

O presente artigo buscou realizar uma releitura crítica e ponderada da obra mais polêmica da Geografia no alvorecer do século XX, "Civilization and Climate", escrita pelo grande geógrafo estadunidense Ellsworth Huntington. Freqüentemente $e$ equivocadamente rotulado de "determinista", este autor prolífico e de teoria ousadas e complexas, foi pioneiro na nascente ciência climatológica, ao contribuir para seu avanço teórico, metodológico e epistemológico. Apesar de raramente lembrado no terreno acadêmico da climatologia, Huntington é um clássico da Geografia e em especial da climatologia, ao lado de expoentes como Humboldt, Vidal de La Blache, Ratzel, Reclus, Sauer, Brunhes, e tantos outros.

Sua obra, considerada a mais volumosa na história da Geografia, lida com grandes hipóteses centrais da Geografia, como a relação sociedade-natureza e a espinhosa e controversa teoria das influências ambientais, principalmente no que concerne a relação entre clima e sociedade, clima e civilização, clima e desenvolvimento. A análise pormenorizada" de "Civilization and Climate" permitiu concluir que além de ser um notório e desprezado clássico da climatologia brasileira, Huntington trouxe grandes avanços para o estudo dos climas em íntima relação com a sociedade. Além de geógrafo e estudante contumaz das civilizações, viajou pelos cinco continentes,

\footnotetext{
9 Sobre essa obra e seu autor, há, em tese de JARDIM DE CARVALHO JR (2011), um estudo aprofundado sobre alguns mitos em torno do que veio a ser conhecido como "determinismo geográfico/ambiental"
}

estudou as oscilações climáticas, estabeleceu os princípios da variabilidade climática, buscou o optimum climático, estudou os resultados da seleção natural, descreveu as qualidades do ozônio e investigou fenômenos cíclicos em várias partes do planeta, principalmente na Ásia, onde se dedicou ao estudo das pulsações climáticas, por meio de várias expedições.

Também foi um dos primeiros a insistir na validade das isopletas, a investigar efetivamente os ciclos, a insistir na medida matemática em detrimento de generalizações inacuradas e a usar extensivamente o coeficiente de correlação, sendo até mesmo considerado 0 precursor da Geografia quantitativa. Trata-se então de um autor de máximo interesse para a climatologia, pela seriedade de suas pesquisas e descobertas, pela complexidade de suas teorias, pela ousadia de suas idéias, e pelo pioneirismo de suas metodologias. 


\section{REFERÊNCIAS BIBLIOGRÁFICAS}

JARDIM DE CARVALHO JR, IIton. Dos mitos acerca do determinismo climático/ambiental na história do pensamento geográfico e dos equívocos de sua crítica: reflexões metodológicas, teórico-epistemológicas, semânticoconceituais e filosóficas como prolegômenos ao estudo da relação sociedade-natureza pelo prisma da idéia das influências ambientais. 2011. $677 \mathrm{f}$. Tese (Doutorado em Geografia Física) Faculdade de Filosofia, Letras e Ciências Humanas, Universidade de São Paulo, São Paulo.

CHAPPELL, John. MATLEY, Ian. "Marxism and environmentalism". Annals of the association of american geographers, vol.57, n.1, março.1967, pp. 203-207.

FREYRE, Gilberto. Casa Grande \& Senzala. Rio de Janeiro, São Paulo: Editora Record, 2000.

HUNTINGTON, Ellsworth. The Character of Races. New York, London: Charles Scribner's Sons, 1927. - Civilization and Climate. New Haven: Yale University Press, 1939
Mainsprings of Civilization. New York: John Wiley and Sons, 1945.

MARTIN, Geoffrey. Ellsworth Huntington; his life and thought. Hamden, Connecticut: Archon Books, 1973.

Civilization and Climate Revisited. Geography and Map Division, vol.96, pp.10-17, 1974

PRADO JR, Caio. Formação do Brasil Contemporâneo. São Paulo: Brasiliense; Publifolha, 2000.

SPATE, Oskar Hermann Khristian. "Ellsworth Huntington". In D.L., Sills, ed., International Encyclopaedia of the social sciences. New York: Macmillian and free press, vol.7, 1968.

WASWO, Richard. Motives of Misreading. Journal of the History of Ideas, vol. 50, No. 2, Apr. - Jun. 1989, pp. 324-332.

* Professor doutor em geografia física pela USP, atualmente professor substituto 40 horas na UFRGS. Email: sinfoniaalpina@terra.com.br 